\title{
Pattern and Outcome of Organophosphorus Poisoning Cases in Bheri Hospital, Nepal
}

\author{
Rajesh Kumar Mandal ${ }^{1}$, Nirmal Shakya ${ }^{2}$, Sanket Kumar Risal ${ }^{3}$ \\ ${ }^{1,3}$ Consultant Physician, ${ }^{2}$ Chief Consultant Physician \\ Department of Internal Medicine, Bheri Hospital, Nepalgunj, Nepal
}

\begin{abstract}

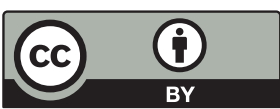

This work is licensed under a Creative Commons Attribution 4.0 Unported License.

\section{BACKGROUND}

Organophosphorus (OP) are frequently used as pesticides and the most common agents of poisoning in developing countries including Nepal. There is paucity of data about characteristics of organophosphorus poisoning in our localities. Therefore, we aimed to evaluate its clinical pattern and factors affecting outcome.
\end{abstract}

\section{METHODS}

It was a cross-sectional study conducted in Bheri Hospital Nepalgunj between 15th July 2019 to 14 th July 2020. The hospital records of patients of acute organophosphorus poisonings were collected. Data regarding age, gender, predisposing factors, duration of hospitalization and outcome of the patients were recorded. Data was analyzed using SPSS 20.

\section{RESULTS}

A total of 53 patients out of which 22(41.5\%) were male and 31(58.49\%) were female with F:M ratio of 1.40: 1. The maximum number of the patients $25(47.16 \%)$ were in the age group of 20 to 40 years. Incidence of poisoning was more common in married patients 36(67.92\%) The suicidal motive for poisoning was found in 49 cases (92.45\%). The most commonly used organophosphorus poison was Dichlorvos 32(60.34\%) followed by methyl parathion 14(26.41\%). Domestic quarrel was the most common predisposing factor 32(60.37\%). 45(84.90\%) of the patients were discharged after successful treatment while there was mortality of 3 patients (5.66\%).

\section{CONCLUSIONS}

Organophosphorus poisoning is a common mode of suicidal attempts leading to morbidity and mortality every year. Strict policies against the free availability and sale of insecticides is required to control organophosphorus poisoning. Mental health education programme should be conducted for the prevention of suicide and poisoning.

\section{KEY WORDS}

organophosphorus poisoning; pattern; outcome

\section{INTRODUCTION}

Organophosphorus (OP) compounds are used as pesticides, herbicides, and chemical warfare agents in the form of nerve gases. ${ }^{1}$ Organophosphorus pesticides inhibit acetylcholinesterase (EC 3.1.1.7) in synapses and on redcell membranes, and butyrylcholinesterase (EC 3.1.1.8) in plasma. ${ }^{2}$ They have potential for induction of systemic illness upon toxic exposure. ${ }^{3,4}$ Most deaths occur due to respiratory and cardiovascular failure, respiratory muscles paralysis and obstruction caused by bronchial secretions and OP induced bronchospasm. ${ }^{5}$

Organophosphorus pesticide self-poisoning is a major clinical and public-health problem across much of rural Asia. ${ }^{6-8}$ According to $\mathrm{WHO}$, one million serious accidental and two million suicidal poisonings due to insecticides occur worldwide, every year, of which 200,000 die and most of these deaths occur in developing countries. ${ }^{9}$ In Nepal 5,317 people committed suicide in the fiscal year 2017$2018 .^{10}$ It has been reported that there are nearly 15 suicides in Nepal each day according to Nepal police. ${ }^{10}$

Poisoning has been a common cause of medical

\section{*Corresponding Author}

Dr. Rajesh Kumar Mandal, Department of Internal Medicine, Bheri Hospital,

Nepalgunj, Nepal | Email: rkmandal338@gmail.com | Phone: +977-9848042427. 
admissions and deaths in Nepalese hospitals. ${ }^{11}$ Deaths from poisoning can be prevented if free availability of such products are restricted and awareness and mental health progamme conducted at community level. However there is paucity of research on organophosphorus poisoning in our region. Therefore this study was conducted with the aim of evaluating clinical pattern, predisposing factors, mortality and outcome of organophosphorus poisoning.

\section{METHODS}

It was a retrospective cross-sectional study conducted in Bheri Hospital, Nepalgunj from 15th July, 2019 AD to 14th July 2020 AD. Ethical clearance for the research was taken from Nepal Health Research Council. The study included all patients presenting to emergency and intensive care units with organophosphate poisoning. Data was collected from admission charts of the patients admitted with organophosphorus poisoning. A total of 53 patients were included in this study. As per the case file, the diagnosis depended on history given by patients or their family about intake of poison and clinical features suggestive of poisoning. Data regarding patient gender, age, marital status, time of ingestion, arrival to hospital, reasoning of poisoning, type of poison, treatment, duration of hospital stay and outcome of the treatment was recorded. The data was analyzed using Statistical Package for the Social Sciences (SPSS)20.

\section{RESULTS}

A total of 53 OP poisoning cases attended Bheri Hospital from 15th July, 2019 AD to 14th July 2020 AD. 22(41.50\%) cases were male and $31(58.49 \%)$ were female. The maximum number of cases were between 20-40 age groups $25(47.16 \%)$ followed by $15(28.30 \%)$ in age group $<20$ years. Married patients outnumbered the unmarried (36/67.02\% vs 17/32.07\%). Table 1.

The mostly used organophosphorus poison was Dichlorvos 32(60.34\%) followed by methyl parathion 14(26.41\%) and cypermethrin+chlorpyrifos $7(13.20 \%)$. The most common motive for poisoning was suicidal 49 cases (92.45\%). Domestic quarrel /marital disputes seemed to be the commonest predisposing factor 32 cases (60.37\%) followed by financial issues 10(18.86\%). (Table 2). The commonest time of presentation of patients in hospital was between 6pm-12 am 22 cases (41.50\%) followed by $13(24.52 \%)$ in the afternoon between 12pm - 6pm. Figure 1. 40(75.47\%) cases presented beyond 1 hour of ingestion of the poison.

Gastric lavage was done in almost all patients in the emergency room. The patient was atropinised and managed in the Emergency ward with other supportive medications. The vital parameters were monitored. Intravenous fluids were administered for hypotension or shock along with dopamine or dobutamine. Oxygen was given for patients with respiratory distress and not maintaining oxygen saturation. Most of the patients were discharged within 5 days of admission 33(62.26\%) Table 3. The average stay in the hospital was 3.94 days. 7 cases (13.20\%) required Intensive Care (ICU) admissions. 5 (9.43\%) of them required respiratory support. Two of them were revived. Overall mortality occurred in 3 cases (5.66\%). 45(88.90\%) of the cases were discharged successfully after treatment. Figure 2.

Table 1. Bio social Data of Patients

\begin{tabular}{|l|l|l|l|}
\hline \multicolumn{2}{|c|}{ Variable } & Frequency & Percentage \\
\hline \multirow{3}{*}{ Sex } & Male & 22 & 41.50 \\
\cline { 2 - 4 } & Female & 31 & 58.49 \\
\hline \multirow{4}{*}{ Age } & $<20$ years & 15 & 28.30 \\
\cline { 2 - 4 } & 20 to 40 years & 25 & 47.16 \\
\cline { 2 - 4 } & $>40$ years & 13 & 24.52 \\
\hline \multirow{3}{*}{ Marital Status } & Married & 36 & 67.92 \\
\cline { 2 - 4 } & Un married & 17 & 32.07 \\
\hline
\end{tabular}

Table 2. Predisposing Factors for poisoning

\begin{tabular}{|l|l|l|}
\hline \multicolumn{1}{|c|}{ Predisposing Factors } & Frequency & Percentage \\
\hline Domestic/Marital quarrel & 32 & 60.37 \\
\hline Financial & 10 & 18.86 \\
\hline Threaten Family & 4 & 7.54 \\
\hline Love tragedy & 5 & 9.43 \\
\hline Medical/psychiatric illness & 2 & 3.77 \\
\hline
\end{tabular}

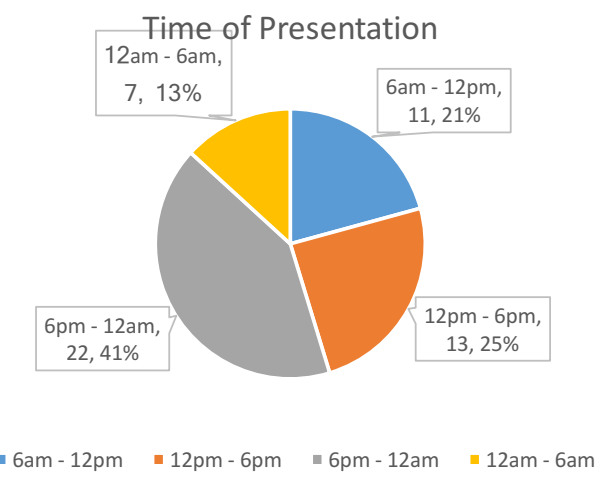

Figure 1. Pie Diagram : Time of Presentation

Table 3. Hospitalization

\begin{tabular}{|l|l|l|}
\hline \multicolumn{1}{|c|}{ Duration of Hospital Stay } & Frequency & \multicolumn{1}{c|}{ Percentage } \\
\hline$<5$ days & 33 & 62.26 \\
\hline 5 to 10 days & 19 & 35.84 \\
\hline$>10$ days & 1 & 0.018 \\
\hline
\end{tabular}

Figure 2. Bar diagram : Outcome 


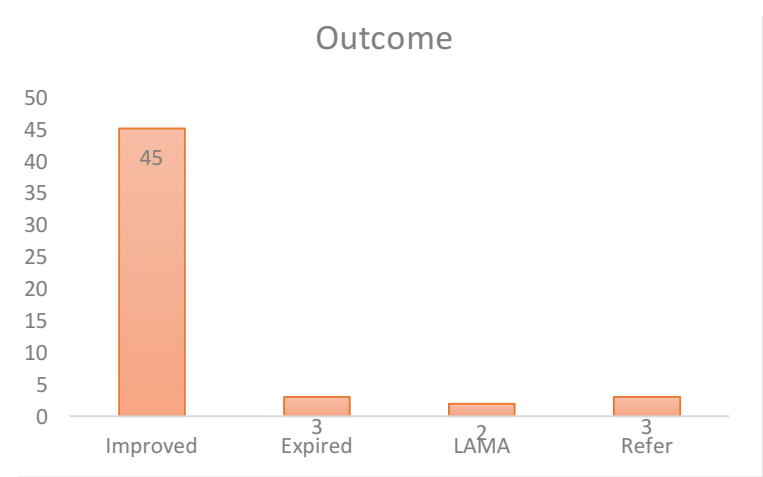

\section{DISCUSSION}

Poisoning by insecticides and pesticides are common presentations in the Emergency department of hospitals over Nepal. Organophosphorus compounds are commonly used in agriculture which is misused as poison. Every year many people lose their lives untimely due to poisoning. Though prevention is the best intervention, timely diagnosis and treatment can save lives. This study consisted of 53 cases of organophosphorus poisoning. The common intention of poisoning was suicide. It was $92.5 \%$ in this study which was consistent with other studies from Nepal, Bhattarai $\mathrm{N}$ et al. $87.2 \%$, Singh $\mathrm{D}$ et al. $97 \% .12,13$ Other studies from India, Chintale KN et al. $82.35 \%$ and Quatar Khan FY et al. $87.3 \%$ and Ethiopia Adinew et al. has $90 \%$ of patients with suicidal intention of poisoning. ${ }^{14-16}$ Another study of OP poisoning in Australia by Emerson found that only $36 \%$ of patients had suicidal intentions which contradicts to the present study. ${ }^{17}$ Most of the patients of poisoning belong to the young adults between 20 to 40 years $25(47.16 \%$ ) in this study. It was consistent with the findings of study by Gaire D et al. $55 \%$ in $15-30$ age group, ${ }^{18}$ Karki et al. $65 \%$ in $15-30$ age group ${ }^{19}$ and Singh D et al. $76 \%$ in 16 to 25 age group. ${ }^{13}$ Similar findings were seen in various studies from India, ${ }^{20-22}$ Dubai, ${ }^{23}$ and Ethiopia, ${ }^{16,24}$ where the maximum patients were between 20 to 30 age group. This age group is a transition period where there is not maturity and emotional instability. A small event can trigger on their nerves and impulsive behaviour may end up with poisoning and suicide attempts.

The poisoning was more in married patients than unmarried in this study $36(67.92 \%)$ which was similar with that of Bhattarai N et al. $74 \%$, Chintale KN et al. $75.3 \%$ and Gaire D et al. $69 \% .^{12,14,18}$

The majority of the cases of poisoning were females 31 (58.49\%) with M:F ratio of 1:1.4. The female predominance of poisoning were seen in Karki et al. ${ }^{19}$ Pokhrel D et al. ${ }^{25}$ with M:F : 1: 1.5. This finding was in agreement with studies conducted in Turkey where M:F ratio was 1: 1.47. ${ }^{26}$ However the study Chintale KN et al. ${ }^{14}$ showed male predominance in OP poisoning. Females predominance in the present study may be due to the fact that they are under stress to manage family, look over the childrens as well as field or business affairs. Moreover domestic violence adds fuel to this situation.

Quarrel in the family was the most common cause $32(60.37 \%)$ of intentional poisoning in this study which was consistent with Shakya RP. et al (70.76\%). ${ }^{27}$ Chintale KN et al..$^{14}$ noted $50.80 \%$ of poisoning was due to social and domestic problems. However study by Marahatta SB et al. showed $37 \%$ which was lower than this study. ${ }^{28}$ Thus familial dispute and quarrel, domestic violence against women has been a major factor triggering for suicidal attempts and poisoning. Most of the poisoning cases occurred between $6 \mathrm{pm}$ to $12 \mathrm{am} 41 \%$ which was similar with Gyenwali et al. where $43.7 \%$ occurred between 6pm 12am. ${ }^{29}$ However study by Gaire $D$ et al. showed that most of the poisoning occurred between 6 am to 12 noon (62\%) and they were taken to hospital within three hours of poisoning(36\%). ${ }^{18}$ I In this study 40(75.47\%) cases reached hospital beyond 1 hour however in the study by Sigdel D et al. $60.7 \%$ of patients reached hospital beyond $1 \mathrm{hr} .{ }^{30}$ Only $14 \%$ reached hospital within $1 \mathrm{hr}$ and $60 \%$ reached between $1-3 \mathrm{hr}$ in the study done by Gyenwali et al. ${ }^{29}$ The delay in presentation to hospital is responsible for greater morbidity and mortality. The delay may be due to untimely recognition of poisoning, delay during transport to hospital, traffic jams, lack of proper health facility near by patients area.

The most commonly used organophosphorus poison was Dichlorvos 32(60.34\%) followed by methyl parathion $14(26.41 \%)$ and cypermethrin+chlorpyrifos $7(13.20 \%)$. This finding was consistent with the study by Gaire D et al. ${ }^{18}$ However it contradicts the other study where methyl parathion was more commonly used than Dichlorvos. ${ }^{31}$ The average stay in the hospital was 3.94 days. 7 cases (13.20\%) required Intensive care admissions. $5(9.43 \%)$ of them required respiratory support. Two of them revived. $45(88.90 \%)$ of the cases were discharged after successful treatment. Overall mortality occurred in 3 cases (5.66\%). This finding was consistent with findings of Gyenwali et al. ${ }^{29}$ Similar outcome of $89 \%$ cure and mortality of $4.5 \%$ was noted in a multi center study from Nepal. ${ }^{26}$

\section{CONCLUSIONS}

Organophosphorus poisoning is common mode of suicide attempts in adolescents, young adults and female. Domestic quarrels being the most common predisposing event for poisoning. Organophosphorus insecticides are chosen due to its low cost and easy availability in the market. Strict rules and regulations should be made regarding selling and purchasing the pesticides. The pesticides must be sold in the presence of a witness known to the client. Public awareness regarding domestic violence and mental health programs should be launched at community level for prevention of suicide and poisoning. 


\section{ACKNOWLEDGEMENT: None}

\section{Conflicting Interest: None}

\section{REFERENCES}

1. Bowls BJ, Freeman JM, Luna JA, Meggs JA. Oral treatment of Organophosphate poisoning in mice. Acad Emerg Med 2003;10:286-87.

2. Lotti M. Clinical toxicology of anticholinesterase agents in humans. In: Krieger R, editor. Handbook of pesticide toxicology. Volume 2. Agents. 2 edn. Academic Press; San Diego: 2001. pp. 1043-1085. [Google Scholar]

3. Dharmani C, Jaga K. Epidemiology of acute organophosphate poisoning in hospital emergency patients. Rev Environ Health. 2005;20(3):215-32.[DOI]

4. Tsai JR, Sheu CC, Cheng MH, Hung JY, Wang CS, Chong IW, Huang MS, Hwang JJ. Organophosphate poisoning: 10 years of experience in southern Taiwan. Kaohsiung $J$ Med Sci. 2007;23(3):112-9. [DOI]

5. Yanagisawa N, Morita $H$, Nakajima $T$. Sarin experiences in Japan: acute toxicity and long-term effects. J Neurol Sci. 2006;249:76-85. [DOI]

6 . Jeyaratnam J. Acute pesticide poisoning: a major global health problem. World Health Stat Q. 1990;43:139-144. [PubMed] [Google Scholar]

7. van der Hoek W, Konradsen F, Athukorala K, Wanigadewa T. Pesticide poisoning: a major health problem in Sri Lanka. Soc Sci Med. 1998;46:495-504. [PubMed] [Google Scholar]

8. Eddleston M, Phillips MR. Self poisoning with pesticides. BMJ. 2004;328:42-44. [PMC free article] [PubMed] [Google Scholar]

9. Jayaratnam $\mathrm{J}$ : Pesticide poisoning as a global health problem. World Health Stat Q 1990; 43 : 139-144.

10. Johnston T, Brickman K, Shrestha R, Shrestha A, Aouthmany S (2020) Organophosphate Poisoning and Suicide in Nepal: A Reflection on the limitations of Behavioral Health Resources. Int J Crit Care Emerg Med 6:097.[DOI]

11. Paudyal BP. Organophosphorus poisoning. JNMA; Journal of the Nepal Medical Association. 2008 Oct-Dec;47(172):251-258. PMID: 19079407

12. Bhattarai N, Rauniyar A, Chaudhary D, Jaiswal S, Banthia P, Rana BB. Patterns of organophosphorous poisoning attending a teaching hospital. JNMA J Nepal Med Assoc. 2006 AprJun;45(162):228-32. PMID: 17189966.

13. Singh DP, Acharya RP. Patterns of poisoning in Nepal. J Inst Med. 2006; 28:3-6. [DOI]

14. Chintale KN, Patne SV, Chavan SS. Clinical profile of organophosphorus poisoning patients at rural tertiary health care centre. Int J Adv Med 2016;3:268-74. [DOI]

15. Khan FY, Kamha AM, Ibrahim AS, D'souza A. One year study of patients with acute organophosphate insecticide poisoning admitted to the intensive care unit of Hamad General Hospital, Doha, State of Qatar. Journal of Emergency Medicine Trauma and Acute Care. 2006;6(2):16-20. [DOI]

16. Adinew G, Asrie A, Birru E. Pattern of acute organophosphorus poisoning at University of Gondar Teaching Hospital, Northwest
Ethiopia. BMC Research Notes. 2017;10(1). [DOI]

17. Emerson GM, Gray NM, Jelinek GA, Mountain D, Mead HJ. Organophosphate poisoning in Perth, Western Australia, 19871996.J Emerg Med. 1999; 17:273-7. [DOI]

18. Gaire D, Mandal L, Shrestha S. Sociodemographic Profile of Organophosphorus Poisoning Case In A Tertiary Care Hospital Of Nepal.2016;16(1)

19. Karki P, Ansari JA, Bhandary S, Koirala S. Cardiac and electrocardiographical manifestations of acute organophosphate poisoning. Singap Med J. 2004;45(8):385-9. PMID: 15284933

20. Gannur DG, Maka P, Narayan Reddy KS.Organophosphorus compound poisoning in Gulbarga region - A five year study. Indian Journal of Forensic Medicine and Toxicology. 2008;2(1).

21. Nigam $M$, Jain AK, Dubey BP, Sharma VK. Trends of Organophosphorus Poisoning in Bhopal region an autopsy based study. Journal of Indian Academy of Forensic Medicine. 2004;26(2):61-5.

22. Rao CS, Venkateswarlu V, Surender T, Eddleston M, Buckley NA. Pesticide poisoning in south india-opportunities for prevention and improved medical management. Trop Med Int Health. 2005;10(6):581-8.[DOI]

23. Sert A, Tarıkçı Kılıç E, Akdemir M, Kavak G. Retrospective Analysis of Organophosphate Poisonings in an Intensive Care Unit in Turkey: A Single-Center Study. Dubai Medical Journal. 2018;1(1-4):13-18. : [DOI]

24. Karalliedde L, Senanayake N, Ariaratnam A. Acute organophosphorus insecticide poisoning during pregnancy. HumToxicol. 1988 Jul;7(4):363-4. [DOI]

25. Pokhrel D, Pant S, Pradhan A, Mansoor S. A comparative retrospective study of poisoning cases in central, zonal and district hospitals. Kathmandu Univ J Sci Eng Technol. 2008; (5):40-8. [DOI]

26. Rehiman S, Lohani SP, Bhattarai MC. Correlation of serum cholinesterase level, clinical score at presentation and severity of organophosphorous poisoning. I Nepal Med Assoc. 2008;47:47-52 PMID: 18709030.

27. Shakya R, Adhikary S, Bajracharya R. Pattern of Acute Poisoning Attending a Tertiary Care Hospital of Western Nepal. Journal of Lumbini Medical College. 2016;4(2):90. [DOI]

28. Marahatta SB, Singh J, Shrestha R, Koju R. Poisoning cases attending emergency department in Dhulikhel HospitalKathmandu University Teaching Hospital. Kathmandu Univ Med J (KUMJ). 2009 Apr-Jun;7(26):152-6. [DOI]. PMID: 20071851

29. Gyenwali D, Vaidya A, Tiwari S, Khatiwada P, Lamsal D, Giri S. Pesticide poisoning in Chitwan, Nepal: a descriptive epidemiological study. BMC Public Health. 2017;17(1). [DOI]

30. Sigdel D, Jha $S$, Kathet $R$, Mainal U, Pokharel R, Dwivedi A. Pattern and Outcome of Acute Poisoning Cases in a Tertiary Care Hospital in Eastern Nepal. International Journal of Contemporary Medical Research [IJCMR]. 2019;6(4). [DOI]

31. Lohani SP. An epidemiological study of poisoning cases Reported to the Nepal Drug and poison information center, Kathmandu, Nepal Drug and Poison Center. 